\title{
The Heat Resistance of Bacterial Spores at Various Water Activities
}

\author{
By W. G. MURRELL AND W. J. SCOTT \\ Commonrealth Scientific and Industrial Research Organization, \\ Division of Food Preservation, Ryde, N.S.W., Australia
}

(Received 2 November 1965)

\begin{abstract}
SUMMARY
The heat resistance of the spores of six species of bacteria varied with water activity $\left(a_{\mathrm{w}}\right)$ at which the spores were heated, although the magnitude of the changes differed greatly between species. At all $a_{w}$ values there was an approximately linear relation between the logarithm of the number of viable spores and the time of heating. The slopes of these straight lines were used to describe the observed death-rates as the time ( $D$ value) required to decrease the population by one log. unit. For all six species the greatest heat resistance was manifest at $a_{w}$ values of about $0 \cdot 2-0 \cdot 4$, the maximum $D$ values at $110^{\circ}$ varying from about 2 to $24 \mathrm{hr}$. At $a_{\mathrm{w}}$ values less than $\mathbf{0 . 2}$ the heat resistance decreased; for spores rigorously dried over $\mathrm{P}_{2} \mathrm{O}_{5}\left(0.00 \mathrm{a}_{\mathrm{w}}\right)$ the $D$ values at $110^{\circ}$ now varied between about 30 sec. and $30 \mathrm{~min}$. When the spores were heated at $a_{w}$ values above $0 \cdot 4$ the resistance of 4 species decreased considerably, being lowest at $1.00 \mathrm{a}_{\mathrm{w}}$; with spores of Bacillus coagulans and $B$. stearothermophilus the heat resistance decreased less at the high $\mathrm{a}_{\mathrm{w}}$ values; at $1.00 \mathrm{a}_{\mathrm{w}}$ their $D$ values were slightly greater than at $0.00 a_{w}$. At the high $a_{w}$ values the $D$ values at $110^{\circ}$ varied from less than 0.1 sec. for Clostridium botulinum type $\mathrm{E}$ to about $40 \mathrm{~min}$. for $B$. coagulans and $B$. stearothermophilus. The $Q_{10}$ for thermal death was about 10 at high $a_{w}$ values, decreasing to about 2 at $a_{w}$ values below $0 \cdot 3$. Under very moist conditions spores of B. stearothermophilus were about 50,000 times more heat resistant than were spores of $C$. botulinum type $\mathrm{E}$; but at $\mathrm{a}_{\mathrm{w}}$ values less than about 0.5 this ratio fell to about 10 . The convergence of this ratio resulted from more than a 100,000-fold increase in the resistance of the type $\mathbf{E}$ spores, and only a 20 -fold increase in the resistance of the spores of $B$. stearothermophilus.
\end{abstract}

\section{INTRODUCTION}

The wide range in the heat resistance of bacterial spores of different species in dilute neutral solutions and foods of high water content is well known but still unexplained. Studies with spores having a 10,000-fold range in heat resistance in dilute phosphate buffer ( $\mathrm{pH} 7$ ) showed, however, that these differences largely disappeared when the spores were heated in a partially dry state (Murrell \& Scott, 1957). There is abundant evidence that spores and vegetative forms are more resistant when heated in substantially dry materials than when heated in dilute aqueous solutions (Oag, 1940; Reed, Bohrer \& Cameron, 1951; Collier \& Townsend, 1956; Townsend, Esty \& Baselt, 1938). In most of these studies the moisture status of the substrate was not controlled, and the results did not provide quantitative 
evidence of the change in heat resistance with change in water content or water activity $\left(a_{w}\right)$. Bullock \& Lightbown (1947), however, found that dried spores stored at $32 \%$ relative humidity $\left(0.32 \mathrm{a}_{\mathrm{w}}\right)$ had a greater resistance than those stored over phosphorus pentoxide. Our earlier results (Murrell \& Scott, 1957) showed that equilibration of bacterial spores with atmospheres of known humidity at $25^{\circ}$, and subsequent heating of the sealed ampoules without the $a_{w}$-controlling solutions, resulted in greatest heat resistance when the spores were equilibrated at an $a_{w}$ of 0.8-0.9 before heating. This treatment very largely abolished the large difference in heat resistance between spores of Bacillus stearothermophilus and Clostridium botulinum type $\mathrm{E}$. The technique used in these studies was, however, unsuitable for controlling the $a_{w}$ value at the temperature of heating. The present paper gives the results of experiments in which approximate control of $a_{w}$ was achieved during heating at temperatures up to $120^{\circ}$.

\section{METHODS}

Organisms and culture conditions. The spores of Bacillus megaterium (Knaysi, Strain C1), B. stearothermophilus ATcC 7953, and Clostridium botulinum type E ATCC 9564 were grown, harvested and enumerated as described by Marshall, Murrell \& Scott (1963). Similar methods were used for the other three organisms except that $C$. botulinum type B ATCC 7949 was grown in peptic digest medium

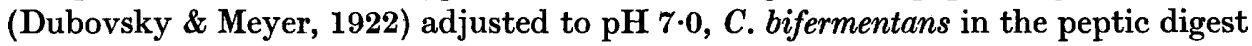
cooked-meat medium of Dubovsky \& Meyer (1922), and B. coagulans on a medium ( $\mathrm{pH} 7 \cdot 2)$ of Casitone $(0.5 \%, \mathrm{w} / \mathrm{v})$, Casamino acids $(0.5 \%, \mathrm{w} / \mathrm{v})$, yeast extract $(0.1 \%$, $\mathrm{w} / \mathrm{v})$, agar $(1 \%, \mathrm{w} / \mathrm{v})$ and a salts mixture (Ohye \& Murrell, 1962).

Equilibration and control of $a_{w}$. Although the $a_{w}$ of spores may be controlled precisely by allowing the spores to reach water vapour equilibrium with solutions of known $a_{w}$ value, the attainment of such equilibrium is dependent on a constant uniform temperature. It is not possible to maintain water vapour equilibrium during the rapid heating and cooling which are inevitably required when spores in sealed containers are exposed to lethal high temperatures for controlled periods of time. The temperature gradients during heating and cooling will result in vapour pressure gradients and cause transfer of water vapour. Furthermore the $a_{w}$ of the spores and of the controlling solutions will itself change with changing temperature. The extent to which water sorption isotherms of spores change with temperature has not yet been determined, but since spores contain substantial amounts of protein it can confidently be expected that for a given water content the $a_{w}$ of the spores will increase as the temperature is increased from say $25^{\circ}$ to $100^{\circ}$. The extent to which temperature affects the $a_{w}$ of the aqueous solutions used is shown in Table 1 . The solutions used were of the concentrations given by Robinson \& Stokes (1955) for the required values at $25^{\circ}$. All results are expressed at the estimated $a_{\varpi}$ (Table 1) at the temperature of heating except where otherwise indicated.

As methods based on equilibration of the spores with $a_{w}$-controlling solutions can give only approximate control during heating, five different procedures were used so that errors would not be constant in magnitude and sign (see Fig. 1).

Method 1. Samples $\left(0 \cdot 2 \mathrm{ml}\right.$.) of an aqueous suspension containing about $10^{8}$ viable spores of one or more species were placed in Pyrex test-tubes $88 \times 9 \mathrm{~mm}$. external 
dimension and freeze-dried. 'These tubes were then constricted to an internal diameter of about $2 \mathrm{~mm}$. midway along their lengths. Above the constriction was placed a small tube $12 \times 7 \mathrm{~mm}$. external dimensions in which was placed $0.2 \mathrm{ml}$. of the solution to control $\mathrm{a}_{\mathrm{w}}$ or a similar volume of dry $\mathbf{P}_{2} \mathrm{O}_{5}$. The larger tube was again constricted above the small inner tube. After freezing the contents in an ethanol + solid $\mathrm{CO}_{2}$ mixture the outer tube was evacuated to about $0.02 \mathrm{~mm} . \mathrm{Hg}$ pressure and the upper constriction sealed. This procedure ensured that the composition of the controlling solution did not change appreciably during evacuation. The ampoules were then stored in the dark at $\mathbf{2 5}^{\circ} \pm \mathbf{0 . 0 5 ^ { \circ }}$ for $2-8$ weeks to enable the spores to reach water-vapour equilibrium with the controlling solution. After equilibration, the ampoules were, without further treatment, completely immersed in an oil or water bath maintained at the desired temperature $\pm 0 \cdot 05^{\circ}$, heated for various times, and then cooled rapidly in iced water.

Table 1. $a_{w}$ values at various temperatures of the controlling solutions used*

Temperature

\begin{tabular}{|c|c|c|c|c|c|c|}
\hline 25 & 70 & 80 & 90 & 100 & 110 & 120 \\
\hline \multicolumn{7}{|c|}{$\mathrm{H}_{2} \mathrm{SO}_{4} \dagger$} \\
\hline $0 \cdot 80$ & 0.815 & 0.818 & $0 \cdot 818$ & 0.820 & $0 \cdot 820$ & $0 \cdot 820$ \\
\hline $0 \cdot 60$ & $0 \cdot 620$ & 0.627 & $0 \cdot 640$ & 0.652 & 0.658 & $0 \cdot 662$ \\
\hline 0.40 & 0.442 & $0 \cdot 450$ & 0.460 & 0.478 & 0.486 & 0.496 \\
\hline $0 \cdot 20$ & 0.244 & $0 \cdot 250$ & $0 \cdot 260$ & $0 \cdot 280$ & $0 \cdot 286$ & 0.296 \\
\hline $0 \cdot 10$ & $0 \cdot 134$ & $0 \cdot 141$ & $0 \cdot 148$ & $0 \cdot 160$ & $0 \cdot 170$ & $0 \cdot 178$ \\
\hline 0.05 & 0.075 & 0.078 & 0.087 & 0.096 & $0 \cdot 104$ & $0 \cdot 110$ \\
\hline \multicolumn{7}{|c|}{$\mathrm{NaOH} \uparrow$} \\
\hline 0.90 & - & 0.909 & 0.909 & 0.909 & 0.910 & 0.910 \\
\hline $0 \cdot 80$ & - & 0.822 & 0.824 & 0.826 & 0.828 & 0.831 \\
\hline 0.60 & - & 0.660 & $0 \cdot 668$ & 0.674 & 0.681 & 0.691 \\
\hline $0 \cdot 40$ & - & 0.497 & 0.510 & 0.526 & 0.540 & 0.554 \\
\hline $0 \cdot 20$ & - & 0.292 & $0 \cdot 308$ & 0.331 & 0.351 & $0 \cdot 369$ \\
\hline $0 \cdot 10$ & - & $0 \cdot 138$ & $0 \cdot 154$ & $0 \cdot 172$ & $0 \cdot 192$ & $0 \cdot 210$ \\
\hline \multicolumn{7}{|c|}{$\mathrm{LiCl}+$} \\
\hline 0.812 & - & - & - & 0.828 & $0 \cdot 838$ & $0 \cdot 848$ \\
\hline $0 \cdot 609$ & - & - & - & $0 \cdot 646$ & $0 \cdot 672$ & 0.692 \\
\hline $0 \cdot 412$ & - & - & - & $0 \cdot 480$ & 0.500 & 0.526 \\
\hline $0 \cdot 200$ & - & 一 & - & $0 \cdot 298$ & 0.316 & 0.334 \\
\hline $0 \cdot 110$ & - & - & - & 0.205 & $0 \cdot 220$ & $0 \cdot 232$ \\
\hline
\end{tabular}

* Composition of solutions from Robinson \& Stokes (1955), Appendix 8.10 and 8.11.

$\dagger$ Calculated from vapour pressure data in the International Critical Tables, vol. III (1928), p. 303 and p. 370 respectively. For $\mathrm{NaOH}$ the values at 90 and $110^{\circ}$ were obtained by graphical interpolation.

$\$$ Values at $100^{\circ}$ were calculated from vapour pressure data in the Landolt-Börnstein tables (1923), p. 1388, and at the other temperatures by graphical interpolation from the boiling point data of Appleby, Crawford \& Gordon, (1934).

Method 2. In this method spores were freeze-dried as before, and the tube placed within a Pyrex test-tube $150 \times 16 \mathrm{~mm}$. external dimensions containing about 0.5 ml. of a solution to control the $a_{w}$ value. The larger tube was constricted and, after freezing and evacuation, sealed in a flame. Equilibration and heating were as in method 1. 
Method 3 was similar to method 1 except that the controlling solution was placed in the lower half of the ampoule, and the spores were freeze-dried in the $12 \times 7 \mathrm{~mm}$. tubes placed in the upper section.

Method 4 was also similar to method 1 except that after equilibration, the seal was completed between the section containing the spores and the upper part containing the controlling solution. In a variation of method 4 a strip of sterile filter paper was placed around the inside of the ampoule about $2 \mathrm{~cm}$. from the



(a) Method 1

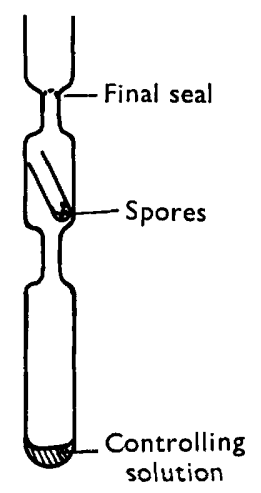

(c) Method 3

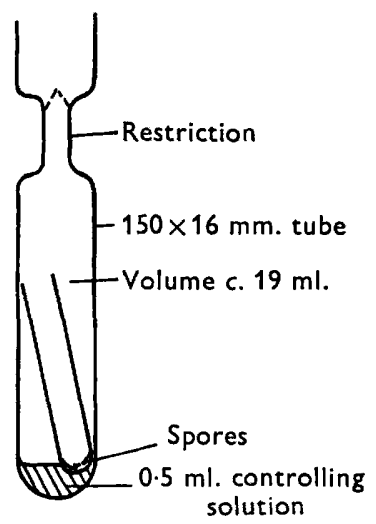

(b) Method 2



(d) Method 5. Bithermal

Fig. 1. Methods of arrangement of the spores and the $a_{w}$-controlling solutions in ampoules during equilibration and heating.

bottom before the first constriction was made around the middle of the $88 \times 9 \mathrm{~mm}$ tube. This filter paper increased, by a factor of about 100, the amount of dry matter and water in that part of the ampoule in which the spores were heated.

Method 5 was based on the bithermal method used by Stokes (1947) to bring aqueous solutions into water-vapour equilibrium with pure water at a controlled lower temperature. The freeze-dried spores in $12 \times 7 \mathrm{~mm}$. tubes were stored in 
vacuum over $\mathrm{CaCl}_{2}$, and subsequently placed inside one arm of a $U$-tube containing about $0.5 \mathrm{ml}$. water in the other sealed arm. The arm containing the tube with the spores was constricted and attached to a vacuum pump. With the arm containing the water in an ethanol +solid $\mathrm{CO}_{2}$ mixture the U-tube was evacuated to about $0.02 \mathrm{~mm}$. $\mathrm{Hg}$ pressure and the constriction sealed. The end containing the spores was heated at $100^{\circ}, 110^{\circ}$ or $120^{\circ}$, and the end containing the water placed in a second thermostat with the temperature adjusted to give the appropriate $a_{w}$ value, e.g. to obtain $0 \cdot 2 \mathrm{a}_{\mathrm{w}}$ at $100^{\circ}$ bath 2 was held at $60 \cdot 4^{\circ}$. The relative positions of spores and the $a_{w}$ controlling solutions are shown in Fig. 1. When placing the sealed $U$-tube in the baths the end with the spores was placed into bath 1 for 1-2 sec. before the end with the water was placed in bath 2 ; this avoided condensation in the end with the spores. For a similar reason, at the end of the heating period the arm of the $U$-tube containing the water was placed into iced water a second before the other end was placed in water at about $10^{\circ}$. After the 1-2 sec. pre-warm of the end with the spores the U-tubes were completely sheathed, with a 3-4 $\mathrm{mm}$. thick layer of copper, over the parts not immersed in the bath, by placing in the copper block illustrated (Fig. 1d); the longer leg of the copper block dipped into the bath at the higher temperature. The pre-warming of the end with the spores was also essential to avoid any 'jumping over' of the water on to the spores when the U-tube was placed in the block. The copper block provided a temperature gradient between the two bath temperatures, but prevented any part of the U-tube decreasing to a temperature below that in the lower bath; this would have produced an $a_{w}$ value lower than the bath temperatures indicated. The copper block also facilitated rapid equilibration by thermal pumping.

The heat resistance of the spores at $1.00 \mathrm{a}_{\mathrm{w}}$ was obtained by heating the spores suspended in $0.05 \mathrm{M}$-phosphate buffer $\left(\mathrm{Na}_{2} \mathrm{HPO}_{4}+\mathrm{KH}_{2} \mathrm{PO}_{4} ; \mathrm{a}_{\mathrm{w}} \mathbf{0 . 9 9 8}, \mathrm{pH} \mathrm{7 \cdot 0}\right)$ or after vapour-phase 'equilibration', with water as the $\mathrm{a}_{\mathrm{w}}$-controlling solution, by one of the methods 1 to 4 .

After heating and cooling, the spores were rehydrated in $10 \mathrm{ml}$. phosphate buffer in $4 \mathrm{oz}$. bottles containing 3-4 doz. glass beads; the bottles were shaken vigorously to disperse clumps.

\section{RESULTS}

\section{Kinetics of disinfection}

Although the rates of disinfection varied widely according to the organism, temperature of heating and the $a_{w}$ value, the general shape of the curves relating the log. of the viable count and the time of heating was usually linear. Some batches of freeze-dried spores of two of the organisms (Clostridium botulinum type $\mathbf{E}$, Bacillus stearothermophilus) gave survivor curves as shown in Fig. 2. These curves showed a relatively rapid death of up to $90 \%$ of the spores and, thereafter, an approximately linear relation between the log viable count and the period of heating. This sudden decrease in the number of viable spores was of the same magnitude irrespective of the temperature of heating and the $a_{w}$ value. This, and the shape of the survivor curve, suggests that the initial high death-rate is probably the destruction rate for spores damaged by the freeze-drying process. The amount of damage would vary from species to species and with each batch of spores freezedried. Rates of heat destruction during the linear second part of the survivor curves 
are, therefore, reported as $D$ values ('decimal reduction time'), these being inversely proportional to the linear regression coefficient, and equal to the time required to reduce the viable population by one log. unit under the conditions obtaining.

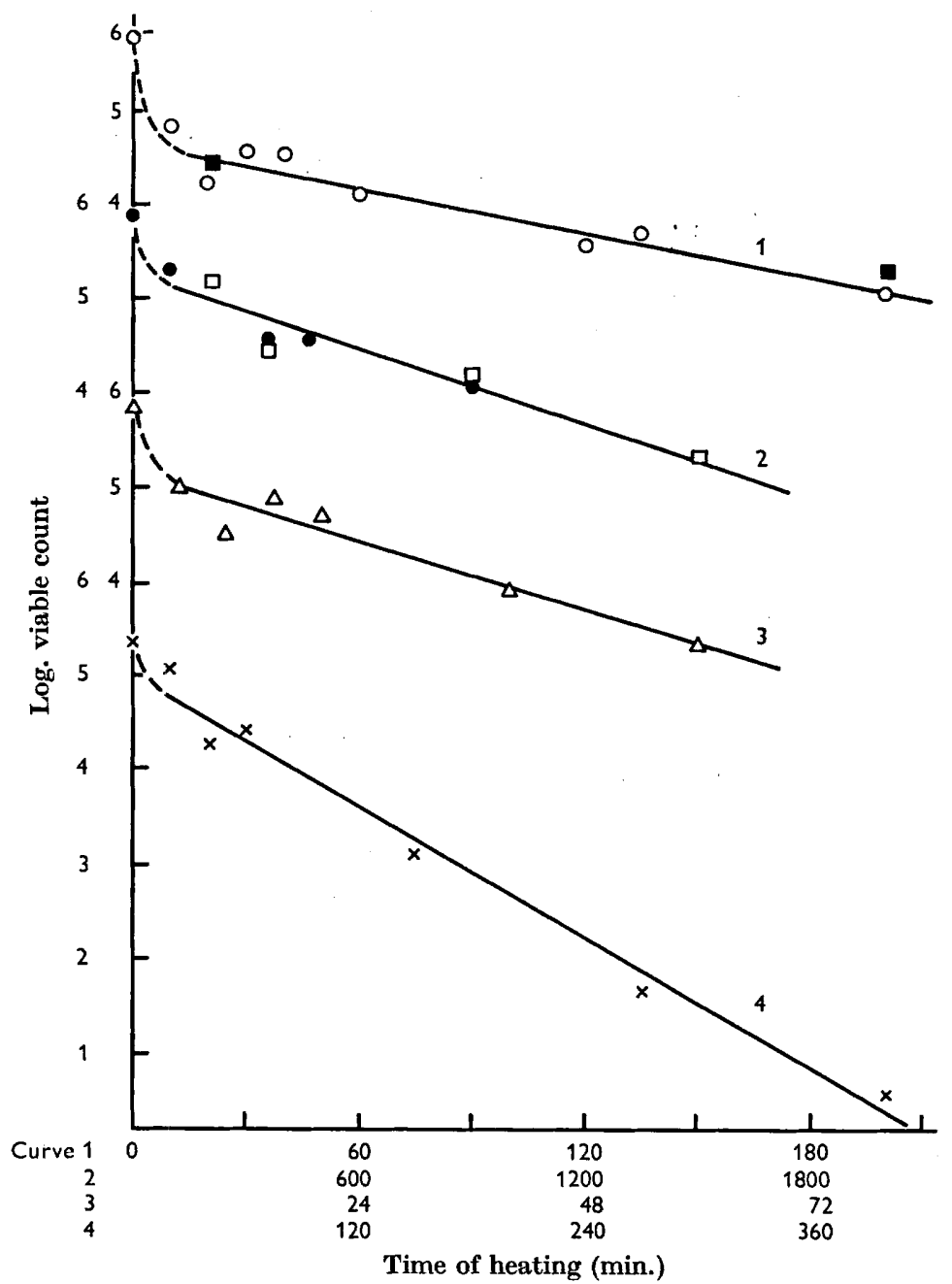

Fig. 2. Curves for two species, summarizing the effect of time of heating on numbers of spores remaining viable after heating under various conditions. Curve 1 , Bacillus stearothermophilus, $0 \cdot 82 \mathrm{a}_{\mathrm{w}}, 110^{\circ}$. Curve $2, B$. stearothermophilus, $0 \cdot 17 \mathrm{a}_{\mathrm{w}}, 110^{\circ}$. Curve 3 , Clostridium botulinum type E, 0.90 $\mathrm{a}_{\mathrm{w}}, 80^{\circ}$. Curve 4, C. botulinum typé E, $0 \cdot 16 \mathrm{a}_{\mathrm{w}}, 100^{\circ}$. Controlling solute $\mathrm{H}_{2} \mathrm{SO}_{4}$. Method 1, except for points marked by squares (Method 2). Ordinate scale for each curve displaced by two log units. 


\section{Comparison of methods for controlling the $a_{w}$ value}

A comparison of methods 1 and 2 at two temperatures and with a 100-fold difference in the number of spores per ampoule is shown in Fig. 3. Clostridium botulinum type $\mathbf{E}$ spores were used for this experiment because of their low heat resistance; the relationship between the $a_{w}$ value and heat resistance was likely to be

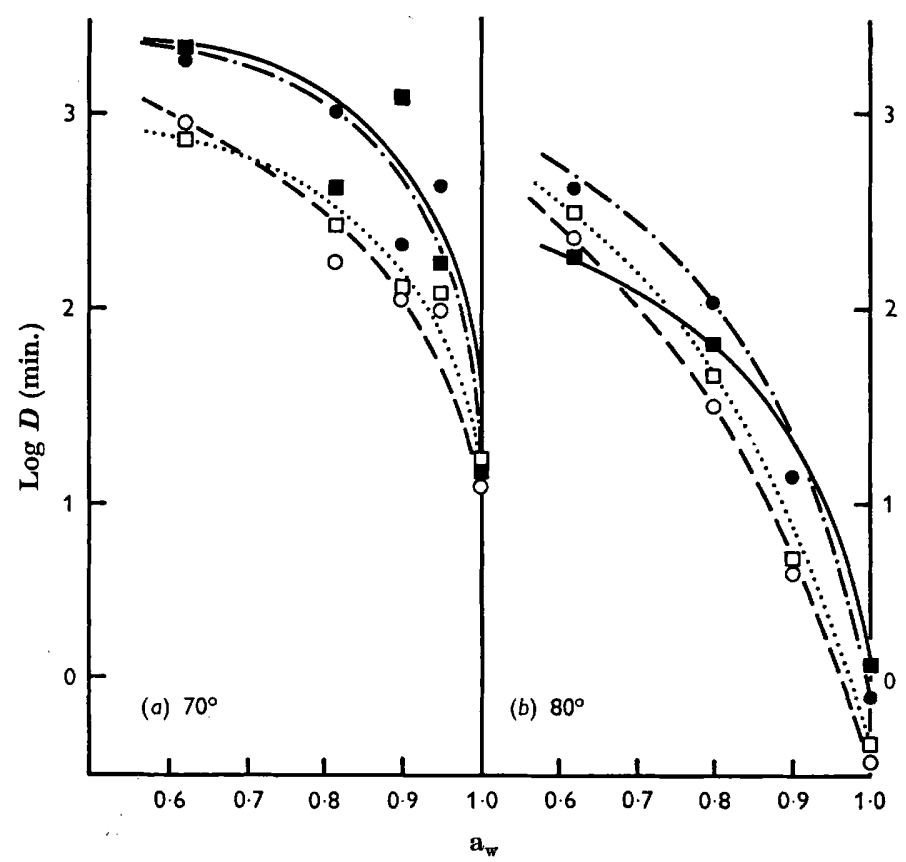

Fig. 3. Fffect of method and temperature of heating, and number of spores on the heat resistance $/ a_{\mathrm{w}}$ response curve for spores of Clostridium botulinum type E. Heated $(a)$ at $70^{\circ}$, (b) at $80^{\circ}$ by Method 1 (circles), 2 (squares). Closed symbols, $10^{8}$ spores/ampoule; open symbols, $10^{4}$ spores/ampoule. $\mathrm{a}_{w}$-controlling solution, $\mathrm{H}_{2} \mathrm{SO}_{4}$. In Method 1 the volume of the ampoule was about $2.5 \mathrm{ml}$. and in Method 2 about $19 \mathrm{ml}$.

more sensitive to changes and lower temperatures of heating could be used to explore the shape of the heat resistance $/ a_{w}\left(H R / a_{w}\right)$ response curve. In all treatments there was a steep increase in heat resistance as the $a_{w}$ value decreased from 1.00 to 0.90 (Fig. 3). There was no apparent difference between the two methods; the number of spores per ampoule having a greater effect on the degree of heat resistance at each $a_{w}$ value than the volume of the ampoule or the arrangement of the spores and the controlling solution.

When methods 1 and 3 were compared no appreciable difference in the results was obtained.

In Fig. 4 methods 1 and 4 are compared. In the early experiments (curve I, from Murrell \& Scott, 1957) with method 4, the controlling solution was not present during heating. The heat resistance increased markedly as the $a_{w}$ value decreased, reaching a maximum at about $0.8 \mathrm{a}_{\mathrm{w}}$. From 0.8 to 0.2 the heat resistance decreased gradually, then decreased further at $0.00 \mathrm{a}_{w}$. In method 1 (curve II, Fig. 4), with 
the controlling solution present, $a_{w}$ values of $0 \cdot 2-0 \cdot 3$ gave maximum heat resistance; the heat resistance increasing to the maximum less rapidly than in method 4 as the $a_{w}$ was reduced.

After equilibration at $25^{\circ}$ the spores would have a moisture content determined by the $a_{w}$ value of the controlling solution at $25^{\circ}$. In method 4 , with the controlling solution removed, there was, even at high $a_{\mathrm{sw}}$ values, so little sorbed water present in the system that when heated to 100 or $110^{\circ}$ the spores lost most of their sorbed water

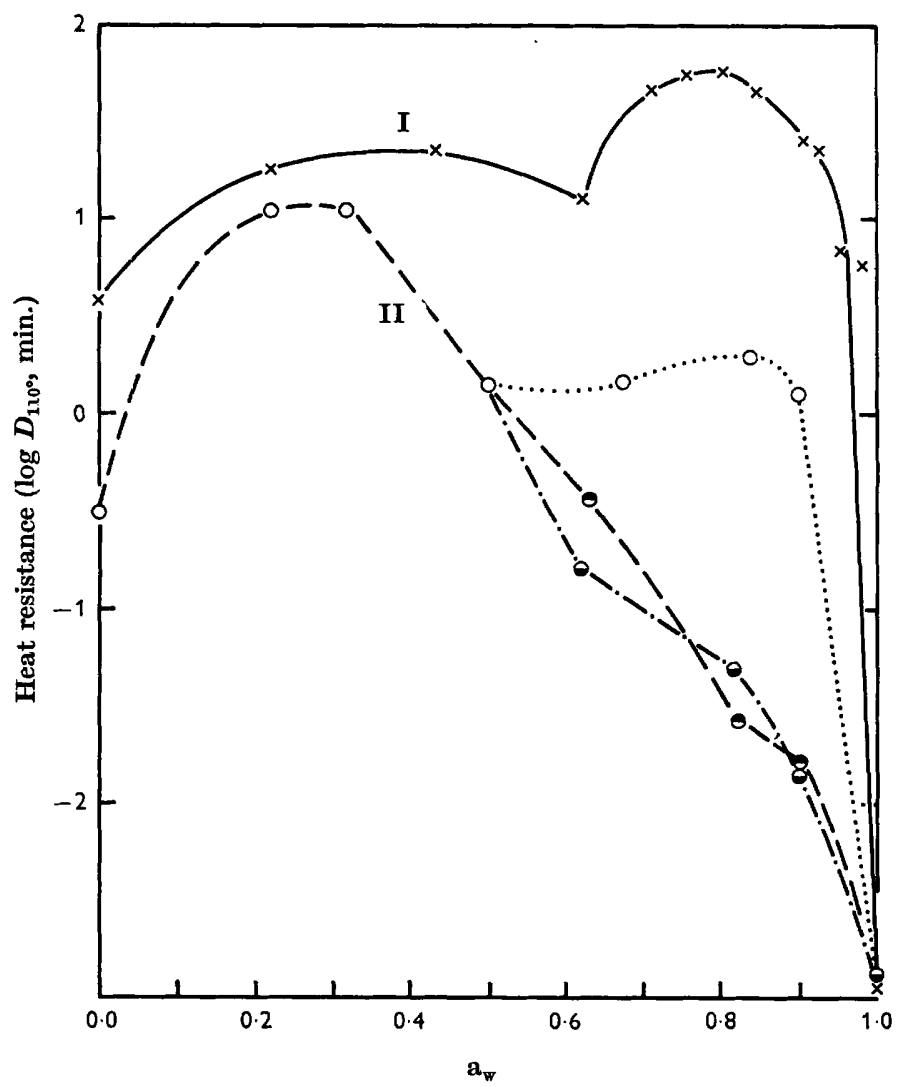

Fig. 4. The effect of the presence of the $a_{w}$-controlling solution during heating and the temperature of heating on the heat resistance/ $a_{w}$ response curve for spores of Clostridium botulinum type E. Solid line, $a_{w}$ controlling solution absent during heating at $110^{\circ}$; points plotted represent $a_{w}$ values at $25^{\circ}$ after equilibration (method 4). Dashed lines, controlling solution $(\mathrm{LiCl})$ present during heating at $110^{\circ}(O), 90^{\circ}(\theta)$, and $80^{\circ}(\theta) ; a_{w}$ value at the temperature of heating (method 1 ). Partly closed symbols indicate points at $110^{\circ}$ estimated from results obtained at $80^{\circ}$ and $90^{\circ}$ assuming a temperature coefficient $\left(Q_{10}\right)$ of 10.

to the surrounding atmosphere within the ampoule. This loss of sorbed water is a direct consequence of the large increase in the density of saturated water vapour with temperature. For example, this is $0.023 \mathrm{mg} . / \mathrm{ml}$. at $25^{\circ}$ but rises to 0.60 and $0.83 \mathrm{mg} . / \mathrm{ml}$. at 100 and $110^{\circ}$ respectively. As in method 1 the volume of the sealed ampoule was about $2.5 \mathrm{ml}$. some $2 \mathrm{mg}$. of water vapour would be needed to provide 
a substantially saturated atmosphere at $110^{\circ}$. When, therefore, the mass of sorbed water was appreciably less than $2 \mathrm{mg}$. it would not be possible to maintain high $\mathbf{a}_{\mathrm{w}}$ values within ampoules heated to $110^{\circ}$. When, however, some 20-50 mg. of filter paper were placed within the ampoule the total mass of sorbed water was appreciably greater than $2 \mathrm{mg}$. and results by method 4 now approached those given by method 1. The data in Fig. 4 show that even when the controlling solution was present some disturbance of the equilibrium occurred at the high $a_{w}$ values. This was, however, less at the lower heating temperatures.

Most of the following results were obtained by method 1. A few obtained otherwise are indicated.

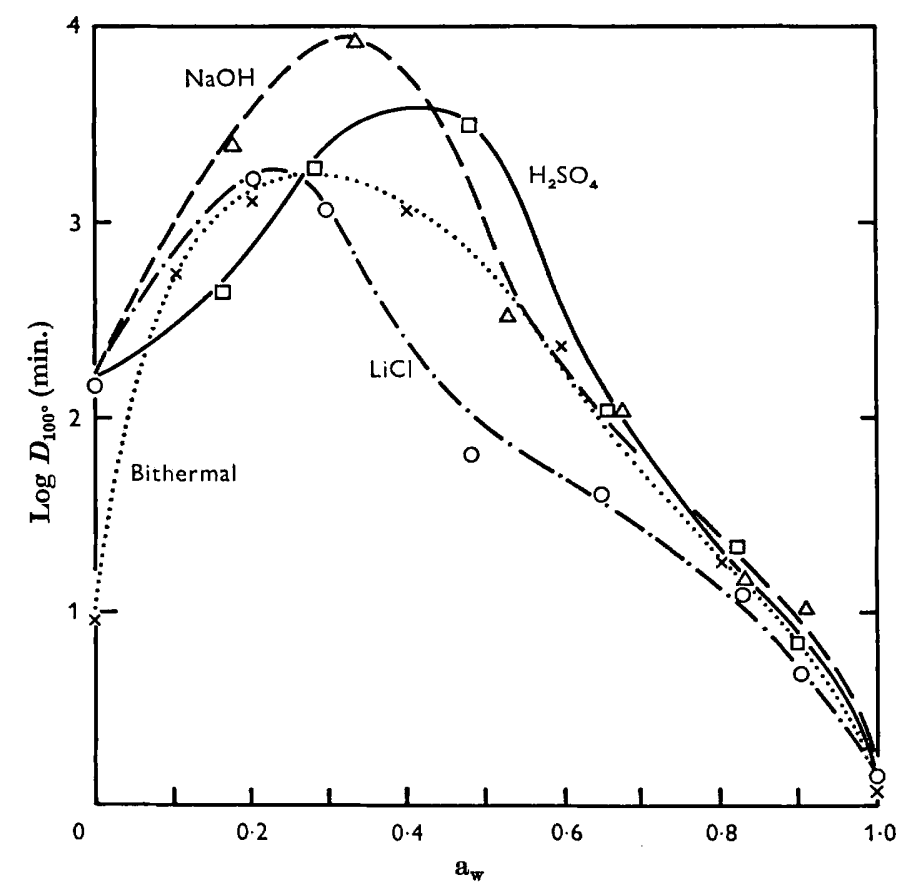

Fig. 5. Heat resistance of spores of Bacillus megaterium at $100^{\circ}$ at various $a_{w}$ values. The freeze-dried spores were equilibrated and heated (method 1 ) in the presence of three different controlling solutions: $\mathrm{H}_{2} \mathrm{SO}_{4}(\square), \mathrm{NaOH}(\triangle)$ and $\mathrm{LiCl}(O)$. Spores were aIso heated with the $a_{w}$ controlled by the bithermal method (Method $\left.5, \times \ldots \times\right)$.

\section{Comparison of controlling solutions}

The relation between heat resistance and the $a_{w}$ value is shown in Fig. 5 for Bacillus megaterium for three different controlling solutions. The heat resistance increased steadily with decreasing $a_{w}$ values until maximum heat resistance was obtained at $a_{w}$ values of $0 \cdot 2-0 \cdot 4$. At these $a_{w}$ values the heat resistance was some 10,000 times greater than at $1.00 a_{w}$. At $a_{w}$ values less than 0.2 the heat resistance decreased sharply. The same type of $\mathrm{HR} / \mathrm{a}_{\mathrm{w}}$ response curve was obtained with each of the three controlling solutions, although the $a_{w}$ values for maximum heat resistance differed. These differences are unexplained. They may, in part at least, have resulted from errors in the estimated $a_{w}$ values of the solutions at the temperatures of heating 
(see Table 1). However, equilibration of the three controlling solutions for $0 \cdot 2 a_{w}$ at $120^{\circ}$ against each other at $120^{\circ}$ indicated that the $\mathrm{NaOH}$ solution lost a small amount of moisture to $\mathrm{H}_{2} \mathrm{SO}_{4}$, and both did to the $\mathrm{LiCl}$ solution. These changes were not large enough nor in the right direction to explain the differences in the $a_{w}$ values for maximum heat resistance. Another batch of spores was heated by using the bithermal method (method 5). The results gave reasonable agreement with those obtained with the controlling solutions.

Results of a more extensive experiment with the bithermal method are shown in Fig. 6. The $H R / a_{w}$ response curve was again very similar to those obtained by method 1 with the three controlling solutions; the maximum heat resistance was well defined in the $0 \cdot 3 a_{w}$ region.

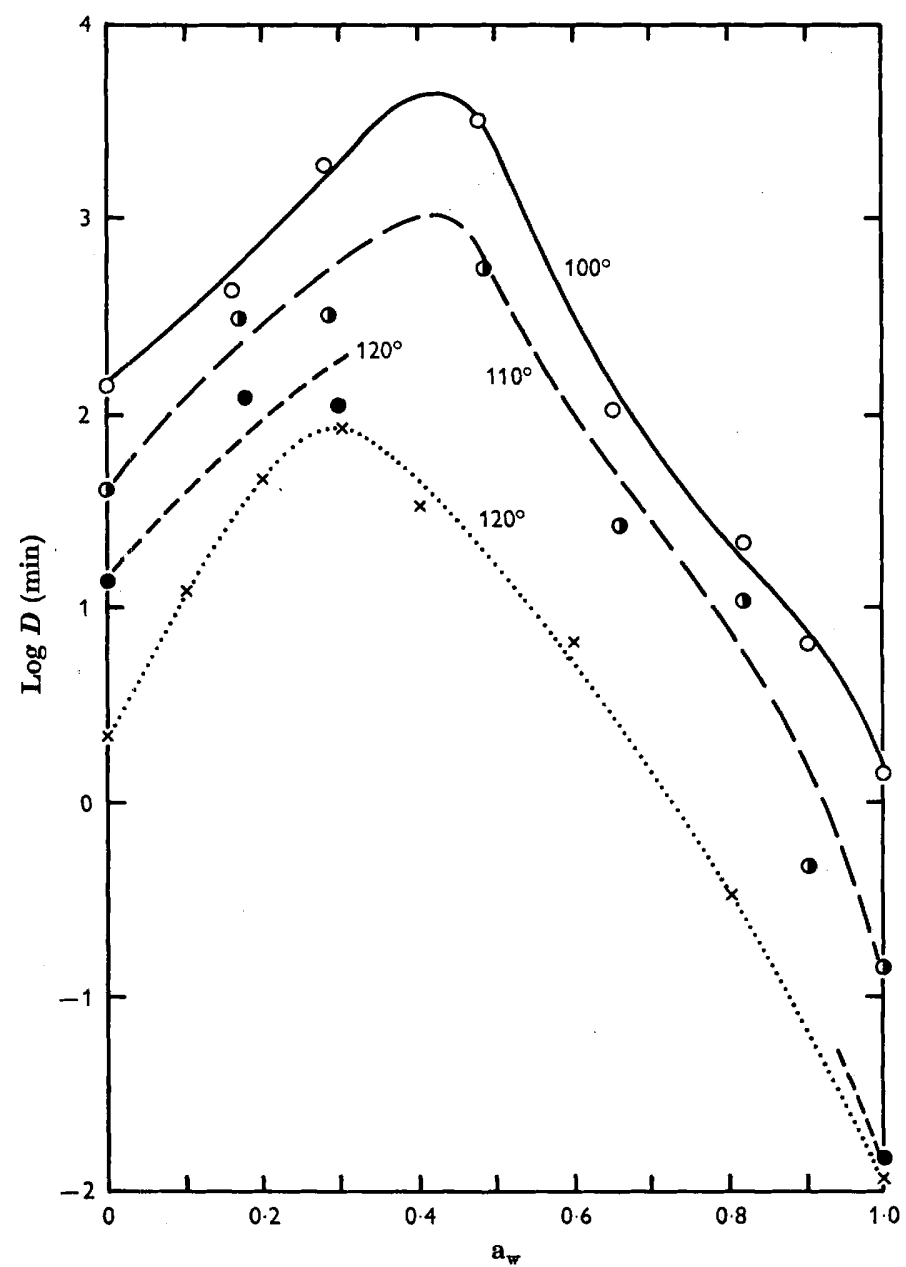

Fig. 6. Effect of the temperature of heating, at various $a_{w}$ values, on the death-rate of spores of Bacillus megaterium. $\bigcirc, 100^{\circ} ; 0,110^{\circ}$; $\mathrm{H}_{2} \mathrm{SO}_{4}$; method 1. Bithermal method, $120^{\circ}, \times \ldots \times$. 


\section{Effect of temperature on heat resistance ( $D$ value) \\ at different $a_{w}$ values}

The effects of $a_{w}$ value on the temperature coefficient of the disinfection process were examined in several experiments. Results for Bacillus megaterium are in Fig. 6 which shows that at 0.00 and $1.00 a_{w}$ the $Q_{10}$ values were about $\sqrt{ } 10$ and 10 , respectively. The latter value is, of course, typical of values reported for spores heated in dilute solutions. At $a_{w}$ values from $0 \cdot 2$ to $0 \cdot 8$ the temperature coefficient

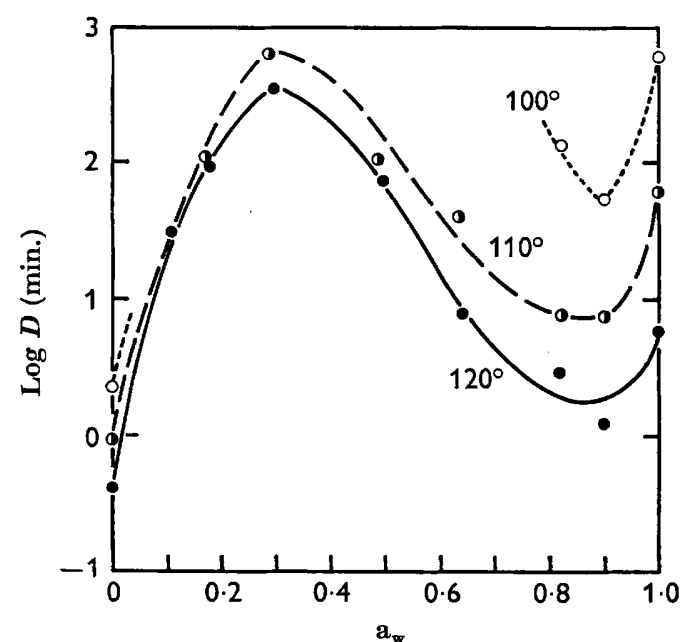

Fig. 7



Fig. 8

Fig. 7 . Effect of the temperature of heating, at various $a_{w}$ values, on the death-rate of spores of Bacillus stearothermophilus. $\mathrm{a}_{\mathrm{w}}$-controlling solution, $\mathrm{H}_{2} \mathrm{SO}_{4}$; method $1.0,100^{\circ}$; $0,110^{\circ} ; 0,120^{\circ}$.

Fig. 8. Comparison of the heat resistance/ $a_{w}$ response curves at $110^{\circ}$ for spores of Clostridium botulinum type $\mathrm{E}$ (circles) and Bacillus stearothermophilus (squares). Spores of the two species in mixed suspension were dried, equilibrated and heated together. Closed circles indicate points estimated from experimental points obtained at lower temperatures by using a $Q_{10}$ value of 10 at high $a_{w}$ values and of 2 at $0.00 a_{w}$. Controlling solution, $\mathrm{H}_{2} \mathrm{SO}_{4}$; method 1 .

was generally less than at 0.9 to $1.00 a_{w}$, but since the individual disinfection rates were somewhat variable the results are not adequate to describe the general relation between the $a_{w}$ value and $Q_{10}$. Results for B. stearothermophilus, shown in Fig. 7, confirm the high $Q_{10}$ values at high $a_{w}$ values and suggest $Q_{10}$ values of 2 or less at $\mathrm{a}_{\mathrm{w}}$ values below $\mathbf{0} \cdot \mathbf{2}$. Results with Clostridium botulinum type $\mathbf{E}$ have also given $\boldsymbol{Q}_{\mathbf{1 0}}$ values of about 10 at high $a_{w}$ values (Fig. 3), decreasing to 2 or less at $a_{w}$ values 
below about $0 \cdot 3$. Although somewhat variable the results suggest that at $a_{\mathrm{w}}$ values below $0 \cdot 3-0 \cdot 4$ there may be important differences between organisms in the temperature coefficients of disinfection.

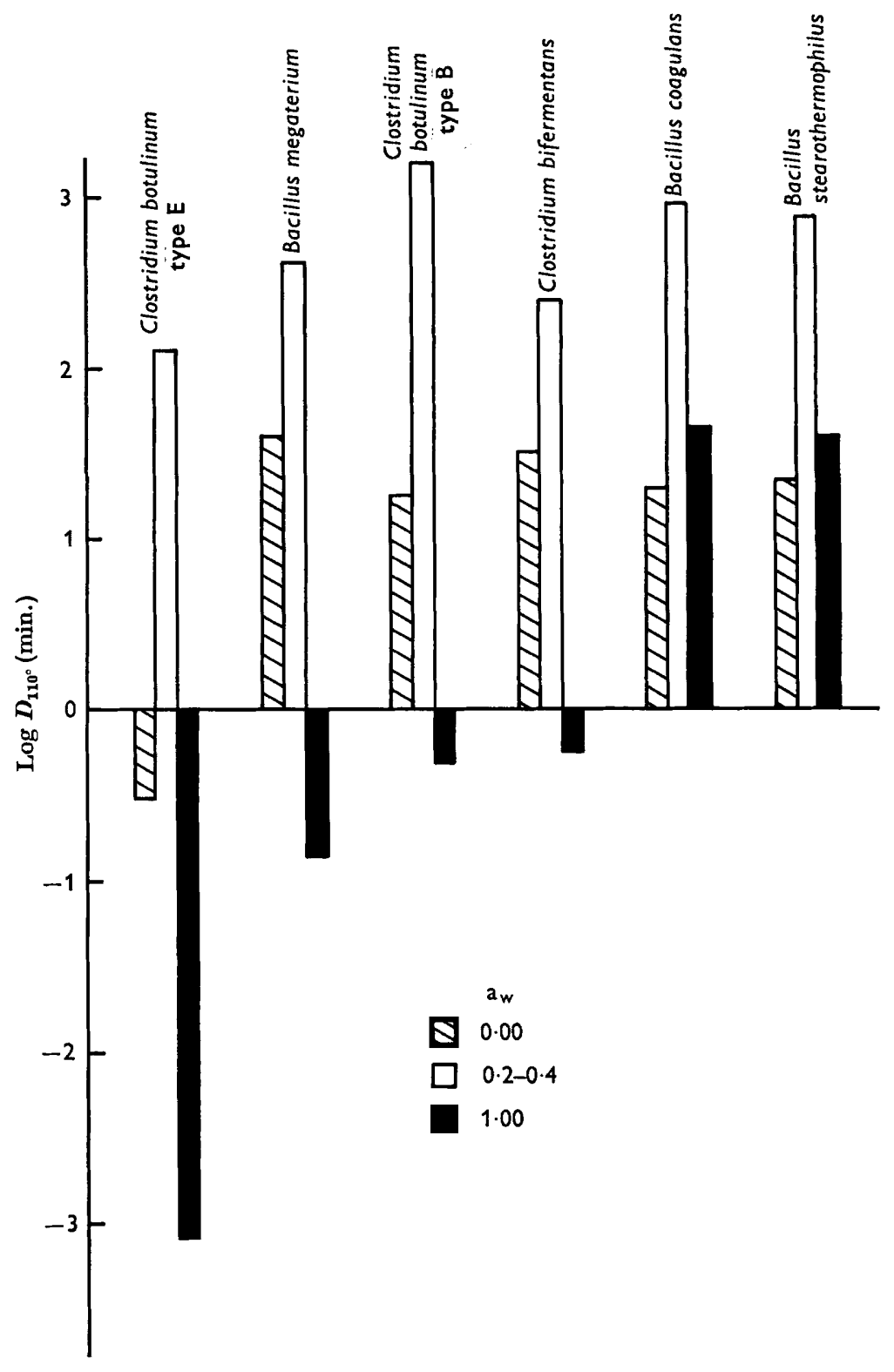

Fig. 9. The heat resistance of the spores of six organisms at each of three values of $a_{w}$ : Q $0.00 ; \square, 0.2-0.4$ (region of greatest resistance);, $0.998(0.05 \mathrm{M}-$ phosphate). The results with Clostrldium botulinum type E, Bacillus megaterium and B. stearothermophilus were obtained by method 1 ; the remainder by method 4 . 


\section{Comparison of the heat resistance of Clostridium botulinum type $\boldsymbol{E}$ and Bacillus stearothermophilus spores at various $a_{w}$ values}

In this experiment spores of the two species were mixed together in suspension before dispensing into ampoules. They were, therefore, freeze-dried, equilibrated and heated under identical conditions at various $a_{w}$ values. Viable counts of the survivors were determined separately. The spores of Clostridium botulinum type $\mathbf{E}$ showed the greatest response to the $a_{w}$ of the heating medium, showing over 100,000 -fold greater heat resistance at $0 \cdot 2-0 \cdot 3 \mathrm{a}_{w}$ than at $1 \cdot 00 \mathrm{a}_{\mathrm{w}}$ (Fig. 8). It should be noted, however, that the calculated $D$ values for $0.6-1 \cdot 00 \mathrm{a}_{w}$ were calculated from values obtained at $70^{\circ}$ and $80^{\circ}$, with an assumed value of $Q_{10}$ over the range 70-110 ${ }^{\circ}$. Maximum heat resistance occurred between $0 \cdot 1$ and $0 \cdot 3 \mathbf{a}_{\mathrm{w}}$.

The spores of Bacillus stearothermophilus showed only about a 20 -fold increase in resistance as the $a_{w}$ value was decreased, reaching a maximum resistance at about $0.2 a_{w}$. The response curve from 1.00 to $0.2 a_{w}$ was not very regular, in that no marked difference in heat resistance occurred between 0.4 and $0.8 a_{w}$. At 0.10 and $0.00 a_{w}$ the heat resistance declined sharply: at 0.00 the heat resistance was even less than that of the spores in water (Fig. 8).

\section{Comparison of heat resistance of six species at various $a_{w}$ values}

Results for three other species (Clostridium botulinum type B; C. bifermentans and Bacillus coagulans; Fig. 9) were, like those for B. megaterium, intermediate between those of $C$. botulinum type $\mathbf{E}$ and $B$. stearothermophilus. The results for these first three species were, however, obtained only by method 4 and are, therefore, of little value in defining the $a_{w}$ values at which maximum heat resistance was attained. Assuming, however, that the amount of sorbed water in each ampoule was between 0.2 and $1.0 \mathrm{mg}$. when the heat resistance was greatest, it can be shown that the corresponding $a_{w}$ values at $110^{\circ}$ would be approximately within the range $0 \cdot 1-0 \cdot 4$. For all six species the heat resistance of spores dried over $\mathrm{P}_{2} \mathrm{O}_{5}$ was appreciably less than the maximum values (Fig. 9). It may also be seen from Fig. 9 that there was only about a tenfold range in the maximum resistance of each species of spore. This approximate equality is in marked contrast to the $10^{5}$-fold difference at $1.00 \mathrm{a}_{\mathrm{w}}$.

\section{DISCUSSION}

In the determination of the death-rates of bacterial spores under various conditions the initial high rate of destruction that occurred with two species was disregarded (Fig. 2). We found previously (Marshall et al. 1963) that freeze-drying and storage of the dried spores damaged a proportion of the spores so that they became stainable on resuspension and heat labile, but not necessarily non-viable. The present results suggest that the damaged spores are also more susceptible to destruction by dry heat. The proportion affected varied between species and preparations; with some species the damage was negligible or not observable. It was, therefore, considered that the second part of the survivor curve during which a linear relation existed between the log number of survivors and the period of heating was the best measure of the death-rate under near-equilibrium vapour-phase conditions. 
Although the methods used to control $a_{w}$ values during heating were imperfect, the results clearly show that bacterial spores manifest their greatest resistance to thermal death when they are practically, but not completely, dry. The results are not sufficiently accurate to define the $a_{w}$ value which gives greatest resistance, but it is probably between $0 \cdot 2$ and $0 \cdot 4$. Method 5 , which appeared from the survivor curves to be very reliable in this region, showed a fairly well-defined maximum at $0.3 \mathrm{a}_{\mathrm{w}}$ for Bacillus megaterium (Fig. 6). The corresponding water contents of spores at $0 \cdot 2-0 \cdot 4 a_{w}$ are of the order of 5-10\% of the dry weight (Marshall et al. 1963). There is, of course, no certainty that the $a_{w}$ value or water contents which give greatest heat resistance will be the same for all species. Similarly for any one species the $a_{w}$ value which gives greatest stability may depend on other environmental factors, as shown for dried vegetative forms (Scott, 1958). Likewise the environment may affect the shape of the heat-resistance/ $a_{w}$ response curve. Some such factor may account for the difference shown in this curve for B. stearothermophilus in Figs. 7 and 8.

The results also show surprisingly little variation in the maximum resistance attained by the spores of several bacterial species. Although only six species were studied this small scatter is of some significance, since the six species studied were selected because of the very wide variations in their heat resistance when heated in dilute buffer solution. This equalization of the heat resistance of several species probably accounts for the observation of Collier \& Townsend (1956) that no correlation existed between resistance to superheated steam and resistance to saturated steam. Koesterer \& Bruch (1962) and Bruch, Koesterer \& Bruch (1963) also observed that spores of Bacillus subtilis var. niger were more heat resistant in the dry state than were those of $B$. stearothermophilus. Similarly, spores of $B$. coagulans and Clostridium botulinum type $\mathbf{B}$ had slightly greater maximal resistance than $\boldsymbol{B}$. stearothermophilus (Fig. 9).

At $a_{w}$ values above $\mathbf{0 . 5 0}$ there were some notable differences between species. For organisms such as Clostridium botulinum type $\mathrm{E}$ and Bacillus megaterium there was a progressive and substantial loss of heat resistance as the $a_{w}$ value approached 1.00. Conversely for spores of $\boldsymbol{B}$. stearothermophilus similar treatments produced only a moderate decrease in resistance. The reasons for these remarkable differences between species are not revealed by the present experiments.

As the $a_{w}$ values approached zero all species of spore became more labile to heat. The change was not inconsiderable, the resistance at $0.00 \mathrm{a}_{\mathrm{w}}$ being only about $1 \%$ of the maximum value. This result certainly indicates that water which hydrates some component(s) of the spore produces marked stabilization against the adverse changes caused by high temperatures. Although the reasons for this stabilization by water are unknown it seems likely that proteins or protein-containing complexes are involved. In this connexion it is of interest that Hornibrook (1952) found that human serum albumin showed greatest resistance to heat denaturation when hydrated with about 210 water molecules per molecule of albumin. This corresponded to an $a_{w}$ value of about 0.15, or 4-7\% of water. Algie \& Watt (1962) showed that keratin is stabilized by a small amount of 'incorporated' water. More precise definition of the role of water in the stabilization of bacterial spores against loss of viability during heating must, however, depend on the results of further experiments. 
The authors are indebted to Miss Kathleen Smith and Miss Jeanette Barr for able technical assistance.

\section{REFERENCES}

AlgIE, J. E. \& W ATT, I. C. (1962). Stabilization of keratin structure by incorporated water. Nature, Lond. 193, 972.

Appleby, M. P., Crawford, F. H. \& Gondon, K. (1934). Vapour pressures of saturated solutions. Lithium chloride and lithium sulphate. J. chem. Soc. p. 1665.

Bruch, C. W., Koesterer, M. G. \& Bruch, M. K. (1963). Dry-heat sterilization: its development and application to components of exobiological space probes. Devs ind. Microbiol. 4, 334.

Bullock, K. \& Lightbown, J. W. (1947). The inactivation of enzymes and microorganisms in oils and powders. II. The effects of drying on the viability of bacteria and their thermolability in powders. Q. Jl Pharm. Pharmac. 20, 312.

Collier, C. P. \& Townsend, C. T. (1956). The resistance of bacterial spores to superheated steam. Food Technol. 10, abstr. no. 4, p. 13.

Dubovsky, B. J. \& MeYer, F. F. (1922). An experimental study of the methods available for the enrichment, demonstration and isolation of $B$. botulinus in specimens of soil and its products, in suspended foods, in clinical and in necropsy material. J. inf. Dis. 31, 501.

Hornibrook, J. W. (1952). Protective effect of moisture on denaturation of human serum albumin by heat. Proc. Soc. exp. Biol. Med. 79, 534.

International Critical Tables of Numerical Data, Physics, Chemistry and Technology (1928) vol. III. New York: McGraw-Hill Book Co.

Koesteren, M. G. \& BRUCh, C. W. (1962). Resistance of dry bacterial spores to sterilization by moist and dry heat. Bact. Proc. p. 30.

Landolt-Börnstein Physikalisch-Chemische Tabellen (1923); 5th ed. Ed. by W. A. Roth \& K. Scheel, vol. 2, table 295, p. 1388. Berlin: Springer-Verlag.

Marshall, B. J., Murrell, W. G. \& Scott, W. J. (1963). The effect of water activity, solutes and temperature on the viability and heat resistance of freeze-dried bacterial spores. J. gen. Microbiol. 31, 451.

MurRell, W. G. \& Scotr, W. J. (1957). Heat resistance of bacterial spores at various water activities. Nature, Lond. 179, 481.

OAG, R. K. (1940). The resistance of bacterial spores to dry heat. J. Path. Bact. 51, 137.

Ohye, D. F. \& Murrell, W. G. (1962). Formation and structure of the spore of Bacillus coagulans. J. Cell Biol. 14, 111.

Reed, J. M., Bohrer, C. W. \& Cameron, E. J. (1951). Spore destruction rate studies on organisms of significance in the processing of canned foods. Fd Res. 16, 383.

Robinson, R. A. \& Stokes, R. H. (1955). Electrolyte Solutions. Appendix 8.11, p. 490. London: Butterworths.

Scotr, W. J. (1958). The effect of residual water on the survival of dried bacteria during storage. J. gen. Microbiol. 19, 624.

Stokes, R. H. (1947). The measurement of vapor pressures of aqueous solutions by bithermal equilibration through the vapour phase. J. Amer. chem. Soc. 69, 1291.

Townsend, C. T., Esty, J. R. \& BAselt, F. C. (1938). Heat-resistance studies on spores of putrefactive anaerobes in relation to determination of safe processes for canned foods. Fd Res. 3, 323. 